\title{
African Archaeologists Honored at the Fourth Shanghai Archaeology Forum, December 2019
}

\author{
Paul J. Lane
}

Published online: 3 June 2020

C) Springer Science+Business Media, LLC, part of Springer Nature 2020

The Shanghai Archaeology Forum (SAF) was established in 2013, by the Chinese Academy of Social Sciences (CASS) under the guidance of Professor Wang Wei (Institute of Archaeology, CASS; President of the Chinese Society of Archaeology) and Professor Chen Xingcan (Director, Institute of Archaeology, CASS). It receives additional sponsorship from the Shanghai $\mathrm{Mu}-$ nicipal People's Government and the logistical and academic support of the Shanghai Academy, Shanghai University, and the Shanghai Municipal Bureau of Cultural Heritage Administration. The Forum has five primary goals, of which the promotion of archaeological investigation of past cultures and civilizations in a comparative global perspective and the relevance of this knowledge to the contemporary world, is the central objective. Other aims are to encourage international collaboration and partnerships between academics and their publics to foster the development of archaeological research around the world; to draw insights from the past that can assist with tackling contemporary global challenges associated with the impacts of climate change, globalization, rapid urbanization, and loss of cultural diversity; to advocate for active engagement with the wider public and to advance public awareness and understanding of the significance of cultural heritage, globally; and to promote archaeological engagement in the development of public policy aimed at the

\section{P. J. Lane $(\bowtie)$}

Department of Archaeology, University of Cambridge,

Cambridge, UK

e-mail: pj129@cam.ac.uk protection and preservation of archaeological resources and cultural heritage.

The first SAF was held at the China Art Museum, Shanghai, in August 2013, and attended by around 500 delegates [1]. Similar meetings have been held biennially since then, in December 2015, 2017, and 2019, in each case hosted on Shanghai University's Baoshan Campus. Although these have been slightly smaller events, but still with between c. 250 and 300 participants, including a large and very willing and helpful cohort of student assistants, they have been no less prestigious, glamorous, or intellectually stimulating. Each Forum comprises three key programs of events: the SAF Awards - which form the focus of the first morning after the opening ceremony; the World Archaeology Keynote Lecture Series; and the Public Archaeology Lecture Series. Nominations for awards are submitted 3-4 months in advance by members of the SAF Advisory Committee, which is international in scope and includes several prominent archaeologists of Africa. The merits of these nominations are assessed against a set of clear criteria by the SAF Selection Committee, which comprises an international panel of experts representing different parts of the world, including Africa. It is this committee that decides, from the long list of nominations, those who will be honored with an award. The award ceremonies themselves have something of the feel of the Oscars or similar showbiz award ceremonies. The auditorium lights are dimmed, and to the sound of dramatic music and dancing spotlights, two glamorous comperes announce the winners in the two categories of achievement-Field Discovery and 
Research. Each Forum is also marked by the presentation of a Lifetime Achievement Award to a senior archaeologist for their contributions to the field [2].

Following the awards, and typically spread over a day-and-a-half to two days, are a series of parallel sessions involving a mix of presenters from China and the rest of the world. These are structured around the theme chosen for that particular year. In 2013, the theme was the Comparative Archaeology of Ancient Civilizations; in 2015, it was Archaeology of Culture and Cultural Contact; and in 2017, the focus was Water, Society, and Civilization. Simultaneous translation from English to Chinese or vice versa is provided for all the talks and events. The organizers also arrange for a conference excursion during the middle of the meeting, to either museums and heritage sites in Shanghai or to key archaeological sites in the vicinity that can be reached within half-a-day by road. Delegates also have the opportunity to join post-Forum excursions to visit other sites and museums elsewhere in China in the company of Professor Wei and the indefatigable Dr. Zhichun Jang (University of British Columbia). It must be mentioned that the behind-the-scenes work of Dr. Jang, during and in the months before the meetings, has ensured the smooth running of the program on each occasion.

The fourth SAF was held on December 14-17, 2019, with the theme "Archaeology of Urbanization and Globalization - The Past for the Common Future of Humankind" (Fig. 1). For the first time, two sub-Saharan African researchers were honored with awards. Professor Shadreck Chirikure (the University of Cape Town and the University of Oxford) received a Research Award for his ongoing research on "Archaeometry and
Urbanism at Great Zimbabwe", and Dr. Abidemi Babatunde Babalola (University of Cambridge) was awarded a Field Discovery Award for his continuing research on the "Archaeology of Glass in Sub-Saharan Africa" [3]. Hearty congratulations to both of them for such justly deserved recognition! [4]

I have attended all four SAF meetings, and the 2019 Forum had by far the largest number of Africa specialists in attendance, and most also presented a paper in one of the parallel sessions. There is a growing awareness among Chinese archaeologists of the wealth of discoveries being made on the African continent and the importance of its archaeology to global conversations about our human story. This recognition goes well beyond the contributions that have been made in the fields of human evolution and Early and Middle Stone Age research. Several Chinese archaeologists have also begun collaborations with Africa-based institutions and researchers, and there is a likelihood that the number of these will increase in the coming decade.

At the same time, China's investment in Africa, especially the financial support (mostly through loans) it has offered for infrastructure and mining projects and urban renewal, has no doubt contributed to the improvement of the quality of life. However, this has also come at a cost to the protection of archaeological heritage (Lane et al. 2016, and references therein). The common absence, in particular, of funding provisions for impact assessments and mitigation work in these projects is particularly lamentable, especially given the high importance that Chinese archaeologists place on archaeological impact assessment in their own country. In fact, many of the spectacular recent discoveries in China
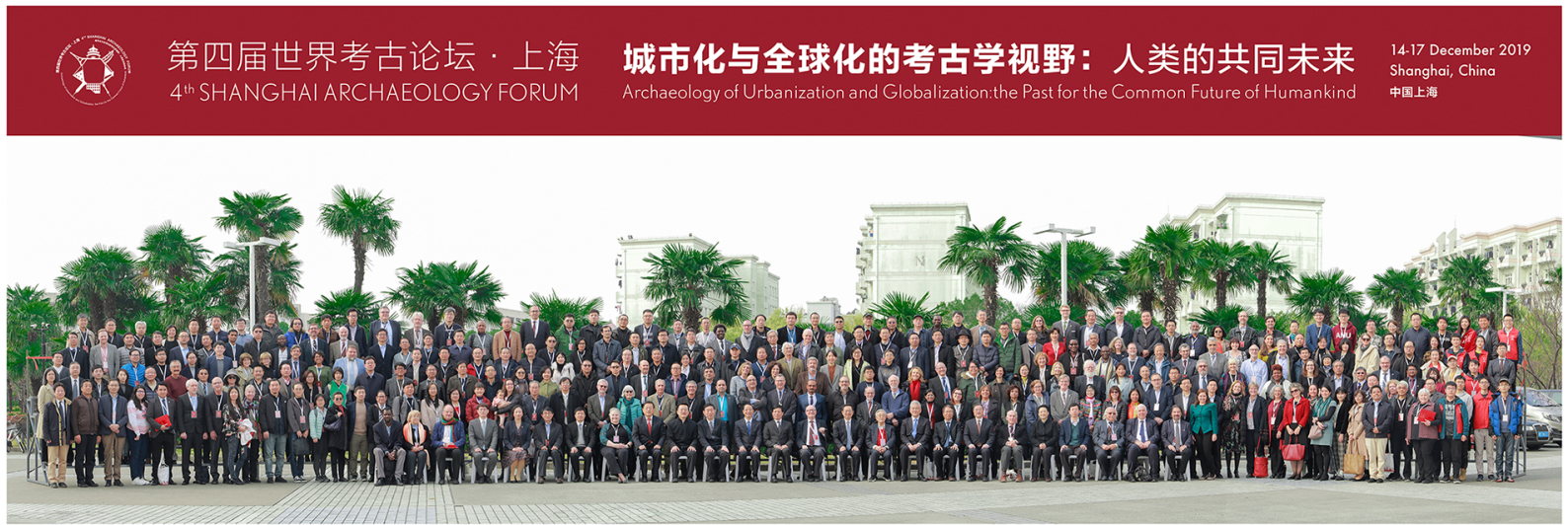

Fig. 1 Group picture of the 4th Shanghai Archaeology Forum 
presented at SAF gatherings seem to have been made within the context of such rescue/salvage projects. This is not to say that Chinese archaeologists do not also recognize this as a problem - and again, the SAF organizers at the 2019 meeting and previous ones acknowledged the need for greater assistance from China to address this shortcoming. The problem, it would seem (and also from talking with Chinese construction project managers on the ground in Mozambique and Kenya), lies higher up the "command chain". Through the auspices of both the Panafrican Archaeological Association and the Society of Africanist Archaeologists, new lines of dialogue with Chinese colleagues could be promoted to discuss how to move forward on these issues. At the same time, national governments on the African continent need to be lobbying their Chinese counterparts when contracts are being negotiated, mindful in particular of the African Union's recognition of the importance of creating "An Africa with a strong cultural identity, common heritage, values and ethics" to the continent's future prosperity (African Union 2014).

\section{References}

Lane, P. J., Kleinitz, C., \& Gao, Y. (2016). Global frictions, archaeological heritage and Chinese construction in Africa.
In T. Hamar (Ed.), The Routledge handbook of archaeology and globalization (pp. 139-156). Abingdon: Routledge.

Union, A. (2014). Agenda 2063: The Africa we want. Addis Ababa: African Union.

\section{Additional Resources}

1. The opening ceremony for the inaugural 2013 Forum can be seen here: https://www.youtube.com/watch?v=K4hvpXFH3 Aw (accessed 13 May 2020).

2. Information about SAF and all award winners: http://121.199.37.213/ (last accessed 13 May 2020).

3. You can find more details of the two Africa award recipients' projects on the SFA website; see, respectively: http://shanghai-archaeology-forum.org/index.php/2019-safar-29 and http://shanghai-archaeology-forum.org/index. php/2019-saf-ad-35 (last accessed 13 May 2020). Longer articles will be published as part of the 2019 SAF Proceedings.

4. The 2019 Opening Ceremony can be watched here: https://www.youtube.com/watch?v=RkuL0m2kYis (last accessed 13 May 2020).

Publisher's Note Springer Nature remains neutral with regard to jurisdictional claims in published maps and institutional affiliations. 